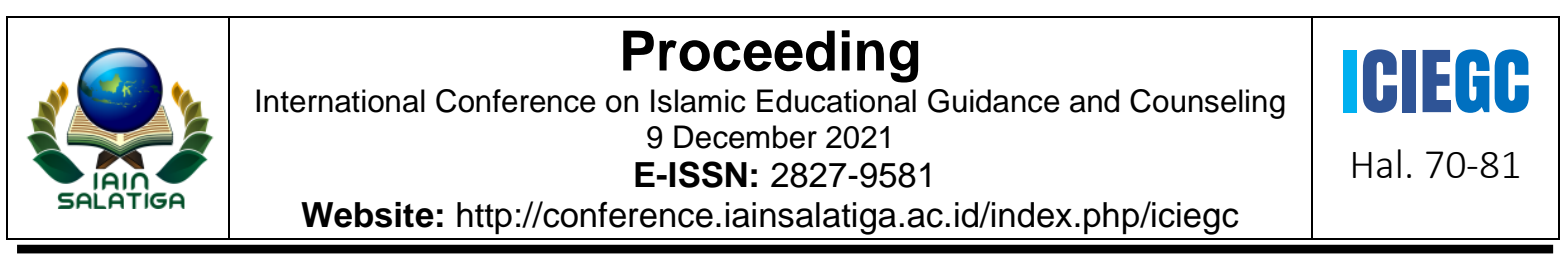

\title{
EFEKTIVITAS LAYANAN BIMBINGAN KLASIKAL BERBASIS PSIKOTERAPI ISLAM UNTUK MENINGKATKAN KONTROL DIRI SISWA DI MTS AL USWAH BERGAS KABUPATEN SEMARANG
}

\author{
Khusnul Maqfiroh ${ }^{1}$, Widayati Lestari ${ }^{2}$ \\ 1,2 IAIN Salatiga
}

\begin{tabular}{l}
\hline Informasi Artikel \\
\hline Penulis Korespondensi: \\
Khusnul Maqfiroh \\
Email: \\
qusnulmaqfira@ gmail.com
\end{tabular}

\begin{abstract}
Self-control is a person's ability to control himself from various aspects such as behavior, feelings and social skills in this case can be done by inculcating spiritual values, emotional mental and good morals in each individual. This study aims to determine the effectiveness of Islamic Psychotherapy-based Classical Guidance services to improve student self-control at MTs Al Uswah Bergas. The method used is quantitative using one group pre-test post-test by doing tests before and after the treatment is given. Data was collected through the distribution of questionnaires and subject documentation. The subjects in this study were class VIII students of MTs Al Uswah Bergas with a population of 124 students and a sample of 31 students. The data from this study were obtained with the help of SPSS for Windows Version 25.0. The results of this study indicate that prior to the implementation of Islamic psychotherapy-based classical guidance, self-control students obtained an average of 86.97 or in the percentage of $58 \%$, which means that they are in the low category. Meanwhile, after being given classical guidance services based on Islamic psychotherapy, the average score was 127.1 or in the percentage of $85 \%$, which means that it is in the high category. This is evidenced by the simple paired t-test which obtained the value of sig. (2-tailed) of $0.000<0.05$, so it can be concluded that the alternative is accepted.
\end{abstract}

\begin{tabular}{l} 
Keyword: Classical Guidance; islamic psychotherapy; self-control; \\
student \\
\hline ABSTRAK \\
Kontrol diri merupakan kemampuan seseorang dalam \\
mengendalikan diri dari berbagai aspek seperti perilaku, perasaan \\
serta kemampuan dalam bersosial dalam hal ini dapat dilakukkan \\
dengan penanaman nilai spiritual emosional mental serta akhlak yang \\
baik pada tiap individunya. Penelitian ini bertujuan untuk mengetahui \\
Efektifitas layanan Bimbingan Klasikal berbasis Psikoterapi Islam \\
untuk meningkatkan kontrol diri siswa di MTs Al Uswah Bergas. \\
Metode yang digunakan adalah kuantitatif dengan menggunakan one \\
group pre-test post-test dengan melakuan tes sebelum dan sesudah \\
diberikannya perlakuan. Pengumpulan data dilakukan melalui \\
penyebaran angket dan dokumentasi subjek. Subjek dalam penelitian \\
ini siswa kelas VIII MTs Al Uswah Bergas dengan populasi 124 \\
siswa dan sampel sebanyak 31 siswa. Data hasil penelitian ini \\
diperoleh dengan bantuan SPSS for windows Version 25.0. Hasil dari \\
penelitian ini menunjukkan bahwa sebelum dilaksanakannya \\
bimbingan klasikal berbasis psikoterapi Islam kontrol diri pada siswa
\end{tabular}


memperoleh rata-rata 86,97 atau dalam presentase $58 \%$ yang artinya masuk dalam kategori rendah. Sedangkan setelah diberikan layanan bimbingan klasikal berbasis psikoterapi Islam memperoleh nilai ratarata 127,1 atau dalam presentase $85 \%$ yang artinya masuk dalam kategori tinggi. Hal ini dibuktikan melalui uji simple paired t-test yang diperoleh nilai sig. (2-tailed) sebesar $0,000<0,05$, sehingga dapat disimpulkan bahwa alternatif diterima.

Kata kunci: Bimbingan klasikal; psikoterapi islam; kontrol diri; siswa

\section{PENDAHULUAN}

Proses pendidikan tidak luput dari peran keluarga, teman, masyarakat dan terkhususnya peran guru di sekolah. Perhatian guru disekolah sangatlah diperlukan untuk perkembangan emosional seorang anak, peran guru mata pelajaran sebagai pengembangan potensi siswa secara akademik harus beriringan dengan potensi siswa dalam hal spiritual dan emosional, dalam hal ini peran guru bimbingan dan konseling sangatlah diperlukan agar siawa tidak terjerumus pada pergaulan bebas.

Bimbingan dan konseling merupakan layanan bantuan peserta didik, baik secara perorangan maupun kelompok, agar mampu mandiri dan berkembang secara optimal, dalam bidang pengembangan kehidupan pribadi, kehidupan sosial, kemampuan belajar, dan perencanaan karir, melalui berbagai jenis layanan dan kegiatan pendukung, berdasarkan norma-norma yang berlaku (Hikmawati, 2016). Dari berbagai layanan yang ada dalam bimbingan dan konseling salah satunya yaitu layanan bimbingan klasikal.

Pada era saat ini berbagai pelanggaran yang dilakukan oleh siswa di sekolah khususnya pendidikan formal masih kerap dilakukan bahkan pelanggaran yang tidak lazim dilakukan seorang siswa kepada gurunya. Misalnya penganiayaan guru honorer hingga terluka dan menimbulkan korban jiwa yang terjadi di SMA N 1 Torjun, Sampang Madura (Maulana, 2019).

Hasil wawancara dengan guru Bimbingan dan Konseling (BK) SMKN 2 Kota Kupang dan beberapa siswa SMKN 2 Kupang menunjukkan bahwa kasus yang sering terjadi yaitu, tawuran, ketidakhadiran siswa dikelas, bolos, keterlambatan siswa masuk sekolah, dan minum minuman keras dimana dalam satu semester kurang lebih 50 kasus yang ditangani dan selama satu tahun ajaran kurang lebih 139 kasus yang ditangani. Sedangkan wawancara dengan siswa menunjukkan bahwa perilaku nakal yang terjadi pada siswa yaitu membolos, lompat pagar saat akan membolos, berkelahi dengan guru, terlambat masuk sekolah, perkelahian antar sekolah bahkan antar kelas atau jurusan (Laure et al., 2020). 
Sementara di MTs Al Uswah Bergas menurut wawancara dengan guru bimbingan dan konseling dengan peneliti berbagai permasalahan seperti diatas juga kerap terjadi seperti halnya tidak mengerjakan tugas, membolos, tidak patuh peraturan, menyemir rambut, masuk terlambat, saling berceloteh yang mengakibatkan bullying. Berbagai pelanggaran disebabkan karena kurangnya kontrol diri pada siswa.

Kontrol diri menurut Chalhoun dan Acocella (dalam Fatimah, 2017) merupakan pengaturan proses-proses fisik, psikologis dan perilaku individu, dengan kata lain serangkaian proses yang membentuk dirinya sendiri, dimana kontrol diri sebagai suatu kemampuan untuk mengatur, menyusun, membimbing serta mengarahkan bentuk perilaku yang dapat membawa individu kearah konsekuensi positif, kontrol diri juga menggambarkan keputusan individu melalui pertimbangan kognitif untuk menyatukan perilaku yang telah direncanakan, atau disusun untuk meningkatkan hasil dan tujuan yang ingin dicapai. Selain itu, juga kemampuan untuk mengontrol dan mengelola faktor-faktor perilaku sesuai dengan situasi dan kondisi untuk menampilkan diri dan melakukan sosialisasi kemampuan untuk mengendalikan perilaku, kecenderungan menarik perhatian, keinginan mengubah perilaku agar sesuai dengan orang lain dan menutupi perasaannya, menurut Ghufron dan Risnawita (dalam Akhmad, dkk., 2019).

Menurut Averil (dalam Marsela dan Mamat, 2019:67) kontrol diri merupakan suatu kemampuan individu untuk memodifikasi perilaku, kemampuan individu dalam mengelola informasi yang diinginkan dan yang tidak diinginkan serta kemampuan individu untuk memilih suatu tindakan berdasarkan suatu yang diyakini. Kontol Diri juga menggambarkan keputusan individu yang melalui pertimbangan kognitif untuk menyatukan perintah yang telah disusun untuk meningkatkan hasil dan tujuan tertentu seperti yang diinginkan.

Menurut Averill (Wulandari, 2020) aspek-aspek yang ada dalam kontrol diri disebut dengan kontrol personal yaitu kemampuan individu untuk mengontrol dirinya yang meliputi kontrol perilaku (behavior control), kontrol kognitif (cognitive control) dan mengontrol keputusan (decisional control).

Menurut Ghufron dan Risnawati (Anggraini, 2019) sebagaimana faktor psikologis lainnya, kontrol diri dipengaruhi oleh faktor internal dan eksternal. Faktor internal yang ikut andil dalam kontrol diri salah satunya adalah usia, semakin bertambah usia seseorang, maka semakin baik kemampuan mengontrol diri seseorang itu. Faktor eksternal yang mempengaruhi suatu individu yaitu dukungan keluarga, pengaruh pergaulan, lingkungan atau masyarakat. 
Oleh karena itu, penanaman kontrol diri sangatlah perlu untuk tiap individu dimana kontrol diri mencakup emosional, tingkah laku dan nilai spiritual. Nilai spiritual dapat ditanamkan melalui kegiatan belajar mengajar atau dapat disebut dengan kegiatan berbasis psikoterapi islam. Psikoterapi Islam merupakan proses pengobatan dan penyembuhan melalui pendekatan psikologis dimana istilah psikoterapi mecakup berbagai teknik bertujuan membantu seseorang mengatasi gangguan psikologis atau emosional dengan mengubah pikiran, perasaan, dan perilaku seseorang agar individu mampu mengembangkan dirinya (Wulur, 2017). Dalam hal ini psikoterapi islam dapat dilakukan dengan berbagai macam metode yaitu: Terapi Al Qur'an. Terapi Doa, Terapi Dzikir, Terapi Shalat, Terapi Mandi, Terapi Puasa, metode Hikmah dan metode Tirakat atau Tasawuf.

Berbagai macam metode atau terapi yang dilakukan dalam penelitian ini terapi yang dilakukan yaitu Terapi shalat Dhuha karna dapat dilakukan pada saat kegiatan belajar mengajar. Salat dhuha dikerjakan pada waktu matahari mulai naik kurang lebih 7 hasta sejak terbitnya kira-kira pukul 7 pagi hingga waktu dzuhur. Salat dhuha dilaksanakan dengan minimal 2 rekaat dan maksimal 8 rekaat (Lestari, 2021).

Terapi dzikir karna dzikir dapat dilakukan kapan saja dan dapat dilakukan setelah shalat dhuha dengan tujuan mendekatkan diri kepada Allah SWT. Dzikir dilakukan dengan cara: 1) Membaca Astaghfirullah (istigfar) sebanyak 3x; 1) Membaca Allahumma antas salam, wa minkassalaam, tabarakta ya dzal dzalaali wal ikraam sebanyak 1x; 3) Membaca Allahumma antas salam, wa minkassalaam, tabaraktarabbana ya dzal dzalaali wal ikraam sebanyak 1x; 4) Membaca Subhanallah (tasbih) sebanyak 33x; 5) Membaca Alhamdulillah (tahmid) sebanyak 33x; 6) Membaca Allahu Akbar (takbir) sebanyak 33x dilengkapi dengan Lailaahaillallahu wahdahu laa syarikala, lahul mulku walahul hamdu wahuwa 'ala kulli syai' in qadir sebanyak 1x (Kamila, 2020).

Dilanjutkan membaca doa penutup sebagai Terapi Doa karena setiap apa yang kita harapkan ketika kita doakan dan kita pasrahkan kepada Allah semua akan mendapatkan hal baik. Dalam hal ini doa yang dipakai yaitu: 1) doa sebelum belajar agar apa yang kita ikhtiarkan dan kita kerjakan pada pembelajaran dapat mudah kita serap nasihat dan hal-hal manfaatnya; 2) Surah Al Asr agar apa yang dikerjakan menjadi sebuah motivasi kedepannya; dan 3) berdoa sesuai keinginan atau harapan yang akan dicapai kemudian dihadiahkan surah Al Fatihah agar semua yang diharapkan mampu kita ingat dan menjadi motifasi dan senantiasa kita wujudkan dalam kehidupan sehari-hari. 
Mengingat bahwa kontrol diri dan psikoterapi islam atau nilai spiritual adalah hal utama yang harus ada pada seorang siswa agar tertata kehidupannya, maka penulis mengangkat judul dalam penelitian ini "Efektivitas Layanan Bimbingan Klasikal Berbasis Psikoterapi Islam Untuk Meningkatkan Kontrol Diri Siswa Di MTs Al Uswah Bergas Kabupaten Semarang” dalam penelitian ini.

\section{METODE}

Metode pendekatan yang digunakan dalam penelitian ini yaitu kuantitatif dengan menggunakan one group pre-test post-test dengan melakukan tes sebelum dan sesudah diberikannya perlakuan. Subjek dalam penelitian ini siswa kelas VIII MTs Al Uswah Bergas dengan populasi 124 siswa dan sampel sebanyak 31 siswa. Teknik pengambilan sampel dalam penelitian ini menggunakan teknik purposive sample dimana pengambilan sampel dengan adanya kriteria dan pertimbangan tertentu. Pengumpulan data dilakukan melalui penyebaran angket dan dokumentasi subjek. Data hasil penelitian ini diperoleh dengan bantuan SPSS for windows Version 25.0.

Pengumpulan data dilakukan melalui penyebaran angket kontrol diri. Dalam penelitian ini terdapat 40 pertanyaan yang kemudian dilakukan validasi Ahli dan validasi menggunakan bantuan SPSS for windows Version 25.0, menghasilkan 36 item pertanyaan yang valid serta dapat disebar kepada responden, dimana dalam menjawab pertanyaan ini menggunakan 4 alternatif pilihan jawaban seperti Sangat Sesuai (SS), Sesuai (S), Kurang Sesuai (KS), dan Tidak Sesuai (TS), pembuatan skala mengacu pada aspek kontrol diri yaitu mengendalikan diri, mengantisipasi informasi dan mengendalikan keputusan. Koefisien reliabilitas dari skala kontrol diri adalah sebesar 0,856 .

Teknik analisis data dalam penelitian ini menggunakan statistik deskriptif, yang dipergunakan untuk menganalisis data dengan cara mendeskripsikan ataupun menggambarkan data yang telah ditemukan tanpa bermaksud membuat kesimpulan secara umum (Sugiono, 2017: 107). Berdasarkan kriteria yang telah dirumuskan perlu menempatkan siswa dalam kelompok-kelompok secara terpisah secara berjenjang sesuai dengan kriteria pengukuran. Menurut Agus Irianto (Siti Habsyah, 2020: 50) dalam melakukan kriteria atau kategorisasi diperlukan rentangan data atau interval data. Dirumuskan sebagai berikut:

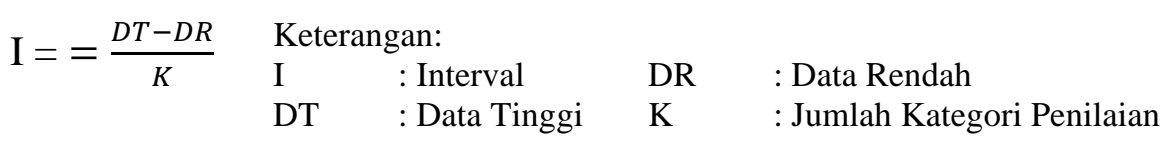


Tabel 1. Kategori Penilaian

\begin{tabular}{ccc}
\hline No & Interval & Kategori \\
\hline $\mathbf{1 .}$ & $36-63$ & Sangat Rendah \\
\hline $\mathbf{2}$ & $64-90$ & Rendah \\
\hline 3. & $91-117$ & Sedang \\
\hline 4. & $118-144$ & Tinggi \\
\hline
\end{tabular}

Instrumen pada penilaian ini terdiri dari 36 butir pertanyaan dengan demikian skor terendah adalah 36, sedangkan skor tertinggi adalah 144. Berdasarkan skor ideal pada variabel kontrol diri tersebut adalah:

$\mathrm{I}=\frac{144-36}{4}=27$

Mengacu pada interval diatas, maka kriteria norma dalam kategori dalam penelitian ini pada tabel 1.

Setelah didapatkannya nilai interval maka perlu dilakukan uji normalitas dan hipotesis. Dalam uji normalitas dalam peneitian ini menggunakan aplikasi SPSS versi 25.0 dengan rumus konglomorov-smirrov dimana pengambilan keputusan adalah dengan melihat angka signifikasinya. Apabila sig> 0,05 maka data berdistribusi normal. Uji hipotesis menggunakan uji Paired Sample T-Test dengan bantuan aplikasi SPSS versi 25.0 untuk mengetahui perbedaan skor sebelum diberikannya treatmen (pretest) dan sesudah diberikannya treatment (posttest).

\section{HASIL DAN BAHASAN}

Pada penelitian ini terdapat tiga tahap yaitu pra-eksperimen, eksperimen dan pasca eksperimen. Peneliti dalam hal ini, sebelum melakukan treatment terlebih dahulu melakukan kegiatan Pra-eksperiman yang bertujuan untuk menentukan populasi dan sampel. Kegiatan ini dilakukan dengan menyebar angket dan memperoleh 31 siswa yang memiliki nilai kontrol diri rendah. Kegiatan pra-eksperimen atau pre-test didapatkan hasil pada kelas eksperimen dengan skor terendah 75 dan skor tertinggi 97, dengan rata-rata 86,97 .

Tahap kedua Eksperimen, Pada tahap ini subjek penelitian diberikan perlakuan dengan menggunakan layanan bimbingan klasikal berbasis psikoterapi Islam dengan menggunakan terapi shalat dhuha, dzikir serta doa, layanan ini diberikan sebanyak 4 kali, dengan menggunakan media yang berbeda-beda sesuai RPL dan kondisi yang memungkinkan. Pertemuan pertama menggunakan Google Classroom dengan materi kontrol diri, kedua grup whatshapp dengan materi kontrol perilaku positif, ketiga google 
meet dengan materi meningkatkan niai spiritual dan yang keempat melalui tatap muka dengan materi pengendalian keputusan.

Setiap pertemuan dilakukan dengan salam, doa sebelum belajar, menanyakan kabar,memberikan semangat, serta menanyakan apakah sudah menjalankan sholat dhuha dan berdzikir atau belum, kemudian diberikan waktu 5-10 menit untuk yang belum melaksanakan dapat menjalankannya namun pada pertemuan terakhir kegiatan shalat dhuha dan dzikir dilaksanakan besama-sama disekolah, hal ini dilakukan agar peneliti tahu sejauh mana perkembangan kontrol diri dalam konsistensi siswa dalam menjalankan treatmen yang diberikan.

Kemudian disampaikan materi, serta setiap siswa diberikan waktu untuk menyampaikan pendapatnya disetiap pertemuan dan dilanjutkan dengan kesimpulan. Kegiatan ditutup dengan membaca surat al asr dan berdoa sesuai keinginan kemudian dihadiahkan surat alfatihah sebagai pengantarnya dan terakhir ditutup dengan salam.

Dalam penelitian ini peneliti juga memberian pemahaman terkait psikoterapi islam melalui materi yang disampaikan, seperti mengkaitkan materi yang disampaian dengan nilai spiritual, contohnya ketika dihadapkan masalah siswa berusaha dengan maksimal mencari jalan keluar dan mengambil keputusan seperti aspek kontrol diri, disisi lain siswa tetap berdoa dan memasrahkan diri kepada sang pencipta.

Tahap Pasca Eksperimen, pada tahap ini dilaksanakan pada akhir pertemuan secara tatap muka, dari beberapa pertemuan dan treatmen yang diberikan kemudian diberikannya angket kembali sebagai nilai post-test.

Pada data pre-test dan post-test yang didapatkan dari angket, maka dapat kita lihat hasil perbandingan antara pre-test dan post-test pada tabel 2.

\section{Tabel 2. Perbandingan Pre-test dan Post-testkelas Eksperimen}

\begin{tabular}{cccc}
\hline No. & Nama & Pre-test & Post-test \\
\hline 1 & AT & 93 & 134 \\
\hline 2 & AZN & 76 & 119 \\
\hline 3 & AF & 86 & 121 \\
\hline 4 & ARF & 90 & 126 \\
\hline 5 & AW & 75 & 118 \\
\hline 6 & AST & 95 & 134 \\
\hline 7 & AA & 88 & 123 \\
\hline 8 & AADR & 96 & 134 \\
\hline 9 & ADL & 79 & 120 \\
\hline 10 & DZF & 93 & 128 \\
\hline 11 & DTD & 84 & 121 \\
\hline 12 & DDF & 86 & 124 \\
\hline
\end{tabular}




\begin{tabular}{cccc}
\hline 13 & DA & 97 & 133 \\
\hline 14 & EK & 87 & 126 \\
\hline 15 & EPP & 91 & 118 \\
\hline 16 & HI & 94 & 132 \\
\hline 17 & JDW & 93 & 131 \\
\hline 18 & MDGP & 80 & 122 \\
\hline 19 & MKN & 95 & 135 \\
\hline 20 & MFA & 76 & 120 \\
\hline 21 & MKM & 89 & 137 \\
\hline 22 & MMF & 79 & 121 \\
\hline 23 & PZA & 84 & 138 \\
\hline 24 & RAPS & 86 & 123 \\
\hline 25 & RH & 83 & 134 \\
\hline 26 & RBA & 81 & 134 \\
\hline 27 & RRWS & 76 & 119 \\
\hline 28 & SH & 94 & 136 \\
\hline 29 & TN & 91 & 128 \\
\hline 30 & VAA & 86 & 122 \\
\hline 31 & VDS & 93 & 129 \\
\hline \multicolumn{2}{c}{$\Sigma$} & 2603 & 3811 \\
\hline \multicolumn{2}{c}{ Mean } & 86,97 & 127,1 \\
\hline Frekuensi & $58 \%$ & $85 \%$ \\
\hline Minimum & 75 & 118 \\
\hline Maximum & 97 & 138 \\
\hline \multicolumn{7}{c}{} &
\end{tabular}

Dari tabel diatas terdapat perbedaan yang signifikan dari kelas eksperimen. Skor pretest yang semula rendah dan sedang menjadi tinggi pada post-testnya.

Setelah data penelitian didapatkan, peneliti melakukan uji hipotesis sesuai dengan ketentuan yang ditetapkan dengan menggunakan langkah-langkah sebagai berikut:

1. Uji Normalitas

Uji normalitas dilakukan sebelum melakukan uji hipotesis, uji normalitas ini dilakukan dengan tujuan mengetahui data yang sudah didapatkan peneliti berdistribusi normal atau tidak. Uji normalitas pada penelitian ini menggunakan SPSS versi 25.0 dengan menggunakan pengujian Kolmogrov Smirnov. Dasar pengambilan keputusan dalam uji normalitas ini adalah apabila sig. > 0,05, maka data berdistribusi normal. Namun apabila sig. $<0,05$, maka data berdistribusi tidak normal. Hasil perhitungan uji normalitas pada tabel 3. Berdasarkan data uji normalitas, diperoleh hasil signifikansi pada kelas pre-test eksperimen sebesar 0,139>0,05, dan nilai signifikansi kelas post-test eksperimen 0,059> 0,05, maka dapat disimpulkan bahwasanya data yang diperoleh peneliti berdistribusi normal. 
Tabel 3. Tests of Normality

\begin{tabular}{llrrr}
\hline & \multicolumn{2}{c}{ Kelas } & \multicolumn{3}{c}{ Kolmogorov-Smirnov } \\
\cline { 2 - 5 } & & Statistic & df & \multicolumn{2}{c}{ Sig. } \\
\hline Hasil & Pre-test Eksperimen & .138 & 31 & .139 \\
\cline { 2 - 5 } Belajar & Post-test Eksperimen & .154 & 31 & .059 \\
Siswa & & & & \\
\hline
\end{tabular}

Tabel 4. Paired Samples Statistics

\begin{tabular}{ccccc}
\hline & Mean & $\mathrm{N}$ & $\begin{array}{c}\text { Std. } \\
\text { Deviation }\end{array}$ & $\begin{array}{c}\text { Std. Error } \\
\text { Mean }\end{array}$ \\
\hline Pre-test Eksperimen & 88.26 & 31 & 6.683 & 1.200 \\
\hline Post-test Eksperimen & 127.10 & 31 & 6.539 & 1.174 \\
\hline
\end{tabular}

Tabel 5. Paired Samples Test

\begin{tabular}{|c|c|c|c|c|c|c|c|c|}
\hline & \multicolumn{5}{|c|}{ Paired Differences } & $\mathrm{t}$ & df & $\begin{array}{l}\text { Sig. (2- } \\
\text { tailed) }\end{array}$ \\
\hline & \multirow[b]{2}{*}{ Mean } & \multirow{2}{*}{$\begin{array}{c}\text { Std. } \\
\text { Deviation }\end{array}$} & \multirow{2}{*}{$\begin{array}{l}\text { Std. } \\
\text { Error } \\
\text { Mean }\end{array}$} & \multicolumn{2}{|c|}{$\begin{array}{l}95 \% \text { Confidence } \\
\text { Interval of the } \\
\text { Difference }\end{array}$} & & & \\
\hline & & & & Lower & Upper & & & \\
\hline $\begin{array}{l}\text { Pre-test } \\
\text { Eksperimen - } \\
\text { Post-test } \\
\text { Eksperimen }\end{array}$ & -38.839 & 2.956 & .531 & -39.923 & -37.754 & -73.147 & 30 & .000 \\
\hline
\end{tabular}

\section{Uji Hipotesis}

Peneliti dalam uji hipotesis ini menggunakan uji paired sample t-test. Dalam hal ini bertujuan untuk mengetahui apakah ada perbedaan rata-rata dua sampel yang saling berpasangan. Uji ini merupakan bagian dari uji statistik parametrik, dimana syarat sebelum menggunakan uji ini, data harus berdistribusi normal.

Menurut Santoso (2014:265) pedoman pengambilan keputusan dalam uji paired sample t-test yaitu jika nilai sig. $<0,05$, maka $\mathrm{H}_{0}$ ditolak dan $\mathrm{H}_{\mathrm{a}}$ diterima. Sedangkan jika nilai sig. > 0,05, maka $\mathrm{H}_{0}$ diterima dan $\mathrm{H}_{\mathrm{a}}$ ditolak. Dalam pengujian ini peneliti menggunakan SPSS versi 25.0. dari pengujian yang dilakukan didapatkan hasil pada tabel 4.

Pada tabel 4. dapat dipaparkan secara singkat statistik deskriptif dari kedua sample pre-test dan post-test. Dari data diatas didapatkan skor rata-rata pre-test 88,26 dan post-test 127,10. Dalam penelitian ini jumlah responden yang digunakan berjumlah 31 siswa. Nilai std. deviation pada pre-test sebesar 6,683 dan post-test sebesar 6,539. Pada data diatas Std. error mean didapatkan 1,200 untuk pre-test dan 1,174 untuk post-test.

Dapat dilihat dari tabel 4 rata-rata kontrol diri pada pre-test $88,26<$ post-test 127,10 . Maka secara deskriptif dapat dilihat perbedaan antara skor rata-rata pre-test dan post-test. 
Selanjutnya untuk membuktikan apakah perbedaan tersebut signifikan atau tidak, maka perlu menafsirkan hasil uji paired $t$-test pada tabel 5.

Dari tabel 5 dapat diketahui nilai sig. (2-tailed) sebesar 0,000<0,05, maka $\mathrm{H}_{0}$ ditolak dan $\mathrm{H}_{\mathrm{a}}$ diterima. Jasi dapat diketahui bahwa ada perbedaan yang signifikan antara skor pretest dan posttest yang artinya layanan bimbingan klasikal berbasis psikoterapi Islam dapat meningkatkan kontrol diri pada siswa kelas VIII MTs Al Uswah Bergas.

Teori Averil menjelaskan bahwa aspek-aspek yang mempengaruhi kontrol diri meliputi mengontrol diri atau kontrol perilaku yang merupakan kesiapan atau tersedianya respon yang dapat secara langsung mempengaruhi atau memodifikasi satu keadaan yang tidak menyenangkan, menerima dan mengolah informasi dengan cara menginterpretasikan informasi yang didapat serta mengontrol keputusan yang kita ambil sesuai yang kita yakini.

Kemudian di dalam penelitian ini juga telah membuktikan bahwa kontrol diri tidak dapat dilihat hanya dengan faktor ekstenal seperti lingungan sekolah, keluarga lingkungan bermain namun juga pada faktor internal seperti usia dan kemauan yang ada dalam diri dalam mengontrol dirinya.

Dari data diatas Peneliti dalam mengetahui efektif atau tidaknya layanan bimbingan klasikal berbasis psikoterapi Islam, melakukan langkah membandingkan nilai pre-test dan post-test dari nilai yang telah diolah dengan menggunakan SPSS 25.0. setelah diberikannya layanan, siswa yang sebelumnya memiliki nilai kontrol diri rendah dan sedang dengan ratarata 86,97 mengalami peningkatan dan memperoleh skor rata-rata 127,1 dimana skor tersebut masuk dalam kategori tinggi.

Pada setiap pertemuan peneliti juga menanyakan bagaimana kabar dan apa yang sudah mereka kerjakan setelah diberikan layanan sebelumnya. Para siswa menjawab bahwa merasa lebih percaya diri, yang semula malu mampu mengontrol dirinya agar tidak malu, yang semula tidak punya harapan apalagi dalam kondisi pademi mereka menjadi ingin selalu mendekatkan diri kepada sang pencipta dan mewujutkan cita-citanya, yang semula selalu mengandalkan temannya dalam mengerjakan tugas menjadi lebih bersemangat dan berusaha untuk menyelesaikannya sendiri dengan penuh tanggung jawab. Yang semula emosional ketika mendengar pernyataan teman tentang diri mereka sekarang menjadi lebih dijadikan motivasi.

Dilihat dari hal tersebut adanya peningkatan kontrol diri siswa dalam tindakan, cara berfikir dan dalam mengambil keputusan untuk dirinya sendiri. Hal ini sesuai dengan teori Averil (Marsela dan Mamat, 2019) dimana siswa dikatakan memiliki kontrol diri yang baik 
ketika aspek-aspek kontrol diri terpenuhi yaitu seperti mampu mengendalikan diri, mampu mengantisipasi informasi, dapat mengendalikan keputusan dimana semua aspek tersebut menyangkut perilaku, kognitif dan keputusan. Sebelum dilakukannya layanan bimbingan Klasikal, kontrol diri pada siswa MTs Al Uswah Bergas mendapatkan nilai rata-rata 86,97 masuk dalam kategori rendah dan setelah diberikannya layanan nilai rata-rata menjadi 127,1 termasuk dalam kategori tinggi dimana jumlah skor tersebut merupakan jumlah atau akumulasi dari semua aspek kontrol diri menurut Averil sesuai dengan indikator judgement instrumen kontrol diri. Serta pemberian layanan bimbingan klasikal berbasis psikoterapi Islam dengan menggunakan terapi sholat dhuha, dzikir setelah shalat duha serta berdoa sebelum dan sesudah belajar dirasa efektif dalam meningkatkan kontrol diri siswa.

\section{KESIMPULAN}

Penelitian ini menghasilkan jawaban atau suatu hipotesis yang menyatakan bahwa Layanan bimbingan klasikal berbasis psikoterapi Islam efektif untuk meningkatkan kontrol diri siswa MTs Al Uswah Bergas Kabupaten Semarang. Hasil ini diperoleh menggunakan Paired Sample T-Test diperoleh nilai sig. (2-tailed) sebesar 0,000 $<0,05$, sehingga $\mathrm{H}_{0}$ ditolak dan $\mathrm{H}_{\mathrm{a}}$ diterima. Rekomendasi penelitian ini diperuntukkan bagi: 1) Bagi peserta peserta didik diharapkan untuk selalu meningkatkan kontol diri, agar individu mampu mengendalikan diri, mampu mengontrol perilaku positif, mampu menilai semua permasalahan yang terjadi secara positif, mampu mengendalikan keputusan, serta mampu mengambil keputusan secara positif; 2) Bagi guru bimbingan dan konseling diharapkan layanan bimbingan klasikal berbasis psikoterapi ini dapat dipergunakan dalam memberikan layanan kepada peserta didik untuk meningkatkan kontrol diri dari segi perilaku, kognitif serta dalam pengambilan keputusan; dan 3) Bagi lembaga diharapkan menjadi salah satu alternatif pemberian layanan bombingan klasikal berbasis psikoterapi Islam bagi siswa.

\section{DAFTAR RUJUKAN}

Akhmad, dkk. (2019). Efektivitas Terapi Shalat Dan Dzikir Terhadap Kontrol Diri Klien Penyalahgunaan NAPSA. Health Information: Jurnal Penelitian, 11(2), 77-90.

Anggraini, I. (2019). Pengaruh Kontrol Diri Terhadap Perilaku Konsumtif Online Shopping pada Wanita Usia Dewasa Awal. (Unpublished Thesis) Universitas UIN Sunan Ampel Surabaya, Surabaya, Indonesia.

Fatimah, N. (2017). Layanan bimbingan Klasikal dalam Meningkatkan Self Control siswa SMP Negeri 5 Yogyakarta. HISBAH: Jurnal Bimbingan Konseling dan Dakwah Islam, 14(1), 25-37.

Hikmawati, F. (2016). Bimbingan dan Konseling. Jakarta: Rajawali Pers. 
Kamila, A. (2020). Psikoterapi Dzikir dalam Menangani Kecemasan. Happiness: Journal of Psychology and Islamic Science, 4(1), 1-12.

Laure, S.H.A.I., Damayanti, Y., Benu, J.M.Y., Ruliati, L.P. (2020). Kesejahteraan Sekolah dan Kenakalan Remaja Siswa Sekolah Menengah Kejuruan. Journal of Health and Behavioral Science, 2(2), 88-104.

Lestari, E. P. (2021). Pembiasaan Salat Tahajud dan Salat Dhuha dalam Menurunkan Tingkat Kecerdasan Santri Putri di Pondok Pesantren Al Barokah Mangunsuman Siman Ponorogo Tahun 20202021. (Unpublished Thesis) IAIN Ponorogo, Ponorogo, Indonesia.

Marsela, R. D. \& Supriatna, M. (2019). Kontrol diri: Definisi dan Faktor. Journal Of Innovative Counseling: Theory, Practice \& Research, 3(2), 65-69.

Maulana, M. A. (2019). Studi kasus Kenakalan Remaja Tingkat Sekolah Menengah Pertama di Kota Sukoharjo. Edudikara: Jurnal pendidikan dan pembelajaran, 4(2), 91-98.

Siregar, S. H. (2020). Efektivitas Teknik Homeroom dalam Layanan Bimbingan Kelompok Untuk Meningkatkan Interaksi Sosial Siswa SMP IT Al-Ikhsan Boarding School Kecamatan Siak Hulu. (Unpublished thesis) Universitas Islam Negeri Sultan Syarif Kasim Riau, Riau, Indonesia.

Sugiyono. (2017). Metode Penelitian Kuantitatif, Kualitatif, dan $R \& D$. Bandung: Alfabeta. Wulandari, A. (2020). Hubungan Kontrol Diri dengan FEAROF MISSING OUT Pada Mahasiswa Pengguna Media Sosial. (Unpublished thesis) UIN Raden Intan Lampung, Lampung, Indonesia.

Wulur, M. B. (2017). Psikoterapi Islam. Yogyakarta: Deepublish. 